\title{
PEDAGOGIA DO ESPORTE E AUTONOMIA: UM ESTUDO EM PROJETO SOCIAL DE EDUCAÇÃO NÃO FORMAL
}

\author{
Gisele Viola Machado \\ Universidade Estadual de Campinas, Campinas, São Paulo, Brasil
}

\section{Roberto Rodrigues Paes}

Universidade Estadual de Campinas, Campinas, São Paulo, Brasil

\author{
Larissa Rafaela Galatti \\ Universidade Estadual de Campinas, Campinas, São Paulo, Brasil
}

\section{Sheila Cristina Ribeiro}

Universidade Estadual de Campinas, Campinas, São Paulo, Brasil

\begin{abstract}
Resumo
O estudo enfoca a perspectiva educacional do esporte em Projetos Sociais, em especial no trato com a autonomia. Para tal, analisa a conduta didática de professores do Programa Ensino Esporte e Juventude (PEEJ) no município de Taubaté-SP, a fim de confrontar a inclusão ou não do estímulo à autonomia no planejamento, com a descrição que os próprios professores fazem de sua prática em relação ao estímulo à autonomia no cotidiano das aulas. A estruturação metodológica do estudo inclui uma revisão bibliográfica inicial, seguida da análise de 50 Planos de Aula de 6 professores do PEEJ, que também responderam a um questionário semi-estruturado acerca do tema autonomia e sua aplicação ao longo das aulas esportivas.
\end{abstract}

Palavras-chave: Esporte - Projeto Social - Autonomia

\section{Introdução}

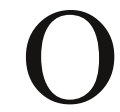

Esporte é um fenômeno social de múltiplas possibilidades, presente em diversos cenários, com diferentes personagens, apresentando, portanto, significados distintos, tal qual o profissional, de lazer, para saúde, estética, representativo, sociabilização e educacional, sendo este último o foco do estudo (GALATTI, 2010).

Para Santana (2005), a função educativa do esporte é inegável, independe do cenário ou dos personagens envolvidos, sendo presente na terceira idade, no Esporte para pessoas com deficiência, em clubes, escolas, organizações não governamentais (ONGs), entre outros. Diante das possibilidades, situamos o estudo no contexto da iniciação esporti- 
va em um Programa Social, fomentado por uma Prefeitura Municipal, no interior paulista.

A iniciação esportiva é definada por Blázquez (1995, p. 41) como a "primera toma de contacto sistemática com un deporte, dirigida por un adulto que tiene la responsabilidad de ejercer dicha función en relación con unos aprendices (jugadores/alumnos), y que tiene como objetivo que el aprendiz logre su autonomía en el dominio de los procesos básicos del deporte". Para o autor, a iniciação esportiva é caracterizada por quatro processos, sendo um de socialização, de ensino-aprendizagem, de aquisição de habilidades, capacidades e destrezas, sendo ainda uma etapa de contato e experimentação.

Apresentado à criança por diferentes agentes, o Esporte em suas diversas modalidades faz parte da cultura infantil, sendo a iniciação esportiva em clubes, academias, prefeituras, escolas ou ONGs o primeiro contato sistematizado da criança com qualquer que seja a modalidade. Os diferentes elementos constitutivos das modalidades esportivas - fundamentos, princípios, características, regras, estratégia e tática do jogo, entre outros - devem ser, aos poucos, apresentados de maneira simples e em nível de exigência adequado às habilidades e capacidades físicas, motoras, cognitivas, emocionais e sociais de uma criança que está iniciando um novo processo. Deve também ter características que a afastem do plano unicamente recreativo, tanto como da busca resultados imediatos.

Diante deste quadro, em Programas Sociais que atendem crianças e adolescentes é importante que não se confunda a perspectiva de não obrigatoriedade de busca de resultados com a ausência dos conteúdos de cada modalidade esportiva. Mais que isso, para ser eminentemente educativo, esse ambiente deve apresentar um programa esportivo fundamentado em proposta pedagógica que oriente o professor na promoção de valores, princípios, regras, convívio social, busca de superação de limites individuais, superação de desafios, vivências práticas, debate em grupo, etc., para que estes alunos possam ser críticos, reflexivos, com condutas norteadas pelos valores e virtudes humanas, buscando de fato uma educação para o convívio social através do esporte.

A fim de garantir tanto o ensino do esporte como o desenvolvimento integral do aluno em Programas Sociais, este texto corrobora com as propostas de Paes e Balbino (2009) e Galatti et al (2008), para os quais o tratamento pedagógico do esporte pelo professor deve atender a dois referenciais: o técnico-tático e o sócio-educativo que correspon- 
dem, respectivamente, aos aspectos de planejamento da aula/treino, táticos e físicos e o fomento de princípios e valores, co-educação, participação, inclusão e autonomia, respectivamente.

Diante das múltiplas possibilidades educativas que o Esporte oferece, destacamos neste artigo a importância do estímulo à autonomia para a formação dos alunos participantes dos Projetos Sócio-Educativos, através das aulas de Esporte, tendo em vista a formação cidadã. Com este foco, o estudo parte do conceito de autonomia, o relaciona com a pedagogia do esporte e avança ao apresentar uma pesquisa de campo de caráter quali-quantitativo, tendo como objetivo investigar a relação entre o conhecimento dos professores sobre o tema autonomia (significado do conceito, se o mesmo pode se aplicado em aulas, formas de aplicação e avaliação das aulas) e sua incidência ou não no planejamento de aulas em um Programa Sócio-Educativo no interior paulista.

\section{Método}

O estudo parte de uma breve revisão bibliográfica acerca da autonomia e seu tratamento na perspectiva da pedagogia do esporte e caminha para pesquisa de campo no Programa Ensino Esporte e Juventude (PEEJ) no Município de Taubaté, S.P. O PEEJ é um Programa Sócio-Educativo que visa estimular o desenvolvimento de forma plena dos alunos participantes através das aulas que oferece. Assim, o estudo foi desenvolvido através de uma pesquisa direta, pois segundo Mattos, Rossetti Júnior e Blecher, (2008), neste tipo de pesquisa há uma relação direta entre a dimensão teórica e a prática, obtida com a observação e experimentação.

O programa estudado atende crianças e adolescentes entre 7 e 14 anos no período inverso ao escolar, de $3^{\mathrm{a}}$ a $6^{\mathrm{a}}$ feira. Possui 5 unidades diferentes na cidade em bairros periféricos, totalizando um atendimento de aproximadamente 2.500 alunos. Oferece aulas de Artes Plásticas, Bijuteria, Capoeira, Dança, Teatro, Oficina da Criatividade, Oficina do Pensar e Educação Física, esta com duração de 1hora e 30 minutos, sendo os alunos divididos em turmas separadas pelo gênero e pela idade, sendo: 7 e 8 anos, 9 e 10, 11 e 12, 13 e 14 anos.

As aulas de Educação Física, oferecidas diariamente, são ministradas por 31 Professores de Educação Física formados e 3 estagiários, com base em um planejamento unificado para todas as unidades, tendo por conteúdo central o Esporte em sua manifestação educacional e 
tendo entre suas finalidades, segundo seu projeto pedagógico, "promover o desenvolvimento da autonomia do aluno preparando-o para o exercício da cidadania".

Dentro do planejamento de Educação Física, O PEEJ conta com um total de 7 turmas, sendo que cada turma possui um plano de ensino específico, com objetivos que buscam atender às três dimensões do indivíduo: motor (habilidades, fundamentos e capacidades físicas), cognitivo (valências psicomotoras e Inteligências Múltiplas) e afetivo-social (capacidades sociais).

Para os alunos de 12 a 14 anos, um dos objetivos previstos é o desenvolvimento de capacidades sociais, sendo um dos conteúdos a autonomia, visto que é a partir dessa idade que o processo de formação da mesma se inicia de forma mais concreta (PIAGET, 2004). É justamente com os professores desse grupo etário que se centraliza a pergunta que originou essa pesquisa: "os professores do PEEJ, responsáveis por esta faixa etária, de fato contemplam a autonomia na sistematização de suas aulas"?

Para respondê-la, foram analisados cinqüenta (50) Planos de Aulas de cada um dos 06 professores (ver anexo 1), que ministram aulas para alunos de 12 a 15 anos. Os planos eram padronizados pela coordenação do projeto, devendo os conteúdos ser apresentados nas três dimensões sinalizadas por Darido e Rangel (2005) (ver anexo 1) Posteriormente, os professores, que atuam no programa há pelo menos 02 anos e até 05 anos, responderam a um questionário com 2 perguntas fechadas e 4 abertas (ver anexo 2), viabilizando constatar proximidade ou distanciamento entre a fala dos professores e seu plano de aula, assim como analisar este conjunto tendo por objetivo responder a pergunta de investigação da pesquisa.

Os Planos de Aula analisados correspondem ao planejamento dos meses de fevereiro e maio de 2010 , mesmo período em que foram aplicados os questionários, cuja análise se desenvolveu em dois momentos: o primeiro qualitativo, referente às questões de caráter fechado, apresentado em forma de gráficos; o segundo, qualitativo, referente às questões abertas, cujas respostas foram agrupadas em quadros e analisadas pelo método comparativo, a partir do confronto entre as respostas dos colaboradores e a literatura especializada.

\section{Sobre a autonomia}


Autonomia é a capacidade de ser governado por si próprio e tomar decisões na convivência sócio-cultural tendo em consideração o respeito à coletividade (KAMII, 1995). Se forma a partir do final da infância quando a criança, normalmente a partir dos onze ou doze anos de idade, adquire a capacidade de estabelecer relações cooperativas, com base em regras morais valoradas em seu contexto, como afirma Piaget (1994, p.23): "Toda moral consiste num sistema de regras, e a essência de toda moralidade deve ser procurada no respeito que o indivíduo adquire por essas regras."

Para o autor, comumente as regras morais são impostas pelos adultos às crianças, que as recebem já elaboradas e, quase sempre, de maneira a não respeitar suas necessidades e interesses. Desta forma, sinaliza para a necessidade de se estimular o desenvolvimento da autonomia a partir do exercício da cooperação, com a tomada de decisões morais na convivência com regras e tendo por princípio o respeito ao grupo no qual se insere. Explica Piaget (2004) que este processo se intensifica por volta dos onze-doze anos de idade, quando a maturação psicológica e as experiências anteriores permitem à criança construir relações com outras pessoas a partir do diálogo e acordos mútuos, sendo decisivas as atitudes de coação (negativamente) ou cooperação (positivamente) dos agentes de convivência - sobretudo os adultos de significância afetiva - na construção da autonomia.

Percebemos, portanto, que para o desenvolvimento da consciência e do respeito às regras existem duas manifestações de comportamento da criança, uma qualificada pelo estágio da coação (imposição do adulto, ou alguém mais velho), caracterizada pela heteronomia e a outra, da cooperação (consciência de normas ideais), caracterizada pela autonomia. Conforme explica Piaget (1994), somente a vivência da cooperação leva à autonomia, pois a criança deixa de acreditar e seguir cegamente as convicções do adulto e passa a analisar criticamente os fatos, estabelecendo relações de discussões tendendo para a tomada de decisão de consciência lógica das relações.

Ser autônomo significa, portanto, estar apto a cooperativamente construir o sistema de regras morais e operatórias necessárias à manutenção de relações permeadas pelo respeito mútuo, ou seja, o ato de governar a si mesmo não deve ser confundido com liberdade completa, pois um sujeito autônomo deve levar em consideração o melhor caminho para a resolução da ação, levando em consideração o outro, como sintetiza Kamii (1995, p.108): "Não pode haver moralidade 
quando se considera apenas o ponto de vista próprio."

A partir do exposto, processos de ensino-aprendizagem desenvolvidos com crianças e que objetivem a formação autônoma das mesmas devem primar por estabelecer um ambiente favorável ao seu desenvolvimento, onde a interação do professor com o aluno deve ser pautada na oportunidade de experimentar, criar, recriar, desafiar, relacionar-se, brincar, respeitar, criticar, discordar, resolver, envolvendo emoções e sentimentos. Essa premissa deve estar presente também em processos de ensino, vivência e aprendizagem esportiva que primem pela formação cidadã, tema a ser explorado no próximo tópico.

\section{Pedagogia do Esporte e a Autonomia}

As possibilidades de conteúdos a serem desenvolvidos pelos professores que trabalham de forma específica com o tema Esporte são amplas e variadas. Darido e Rangel (2005, p.65) ao revisarem Coll et al, Zabala e Libâneo, afirmam que: "conteúdos de ensino são o conjunto conhecimentos, habilidades, hábitos, modos valorativos e atitudinais de atuação social, organizados pedagógica e didaticamente, tendo em vista a assimilação ativa e aplicação pelos alunos na sua prática de vida." Complementam as autoras:

(...) desta mesma forma, quando nos referimos a conteúdos, estamos englobando conceitos, idéias, fatos, processos, princípios, leis científicas, regras, habilidades cognoscitivas, modos de atividade, métodos de compreensão e aplicação, hábitos de estudos, de trabalho, de lazer e de convivência social, valores, convicções e atitudes. (DARIDO; RANGEL, 2005, p. 65)

Com isso, os conteúdos a serem ensinados na prática esportiva vão além dos técnicos-táticos, englobando também os elementos sócioeducativos, o que se fortalece na perspectiva da pedagogia do esporte (PAES, 2002; GALATTI et al 2008). A fim de garantir o respeito a estes dois referenciais, é complementar a proposição de Darido e Rangel (2005) em organizar os conteúdos em três dimensões: (1) Conceitual, relativo ao que se deve saber; (2) Procedimental, relacionado ao que se deve saber fazer; (3) Atitudinal, como se deve ser.

É considerando o referencial sócio-educativo que incluímos a autonomia como um conteúdo a ser planejado e desenvolvido pelos pro- 
fessores, tendo em vista suas três dimensões: na CONCEITUAL o aluno deverá compreender o que significa autonomia, sua relevância social, a importância de cooperar e respeitar o próximo; na dimensão PROCEDIMENTAL o aluno deve ter acesso à prática de atividades em grupo, já que são nelas que a capacidade de cooperar - prerrogativa para a formação da autonomia - é exigida, sendo destacadas as estratégias didáticas fundamentadas no princípio global-funcional (GALATTI, DARIDO e PAES, 2010); na dimensão ATITUDINAL o professor deve assumir procedimentos pedagógicos que favoreçam aos alunos tomar decisões e enfrentar desafios de convivência e ter atitudes autônomas através do respeito, da cooperação, do diálogo e dos questionamentos professor-aluno e, sobretudo, aluno-aluno (FERREIRA, ; SCAGLIA e SOUZA, 2004; SANTANA, 2003). Corrobora com a perspectiva Freire e Scaglia (2006), para os quais a aula de esporte, se assim orientada pelo professor, é ambiente extremamente favorável para o exercício da convivência, cooperação e autonomia.

Portanto, no planejamento de aulas de esporte na perspectiva da pedagogia do esporte e na expectativa da formação para a autonomia, é necessária a superação da redução das aulas ao referencial metodológico e que o referencial sócio-educativo deixe de ser parte do currículo oculto e seja elemento organizado e sistematizado nos projetos e currículos pedagógicos, planos de ensino e planos de aula (nem sempre existentes), dando suporte para a aplicação de práticas que primem pela educação do sujeito.

Tal prerrogativa pode se inserir nos diferentes ambientes de oferta esportiva com intenção educacional, tais quais a escola, as ONGs, escolas de esporte, prefeituras etc. Na seqüência do estudo, apresentamos um estudo de caso em um programa sócio-educacional promovido pela Prefeitura Municipal de Taubaté, o qual se propõe a educar crianças e jovens a partir de diferentes atividades sócio-culturais, dentre as quais o esporte. Ainda que consideradas as restrições de um estudo de caso às especificidades do ambiente estudado, a pesquisa busca contribuir para a ampliação do debate das possibilidades educacionais do esporte e em como estas de fato podem estar presentes nas aulas de forma intencional e planejada.

\section{Pesquisa de Campo no PEEJ: procedimentos de pesquisa, resulta- dos e discussão}


O estudo do caso tem início com a análise de Planos de Aula do grupo de professores investigados, a fim de verificar se houve a preocupação por parte dos professores em planejar as aulas incluindo o estímulo à autonomia, assim como possibilitar relacionar, na seqüência, o conteúdo dos planos com as falas dos professores. Foram analisados 300 Planos de Aula. Conforme ilustra o gráfico 1, há a presença do tema autonomia no plano de aula em quatro dos seis professores investigados, sobretudo na dimensão atitudinal e em porcentagem sempre inferior a $20 \%$ do total de aulas planejadas.

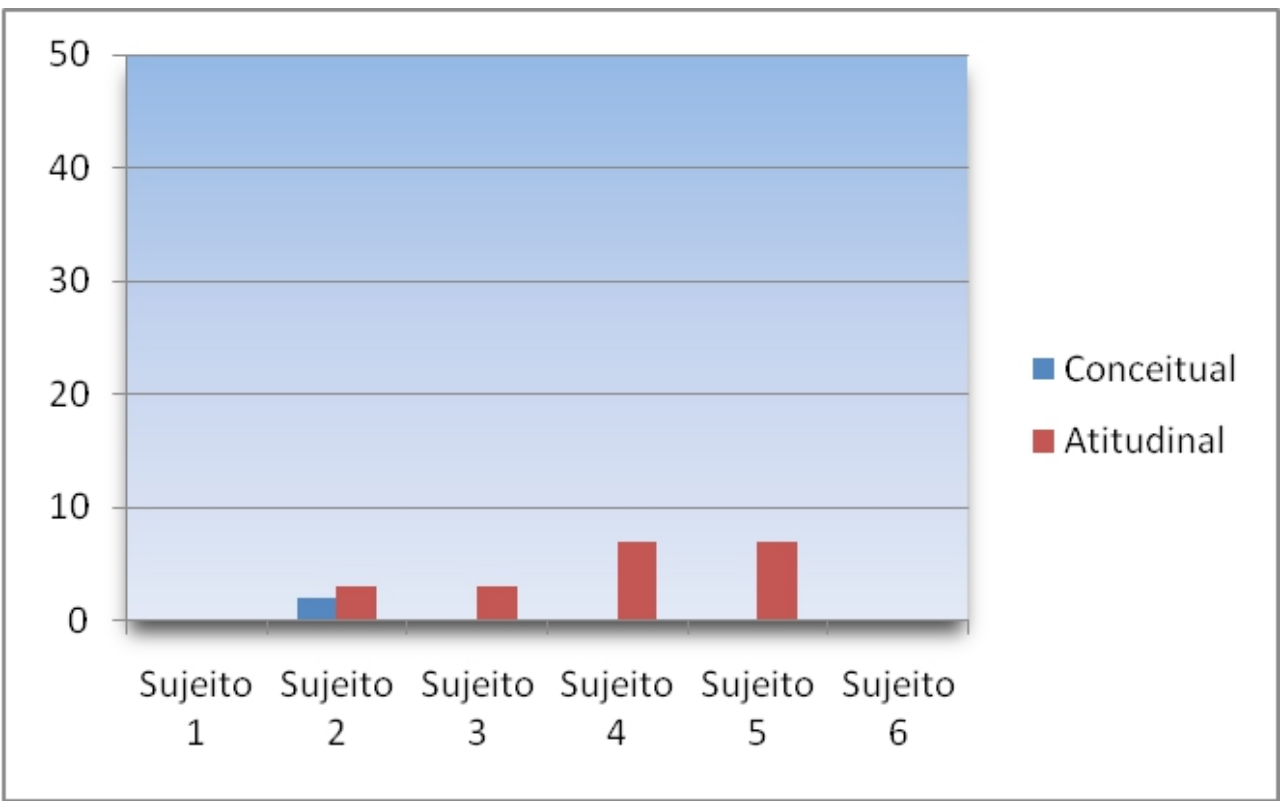

Gráfico 1: Análise de planos de aula

Após a análise dos planos de aula, foram aplicados os questionários com cada um dos seis professores investigados. Os resultados obtidos foram analisados e discutidos em dois blocos distintos: o primeiro diz respeito a uma análise das perguntas fechadas, relativas à visão do professor quanto às finalidades do Esporte no PEEJ, se a autonomia pode ser trabalhada nas aulas de Esporte e se o professor planeja suas aulas com um dos objetivos voltados ao desenvolvimento da autonomia do aluno; o segundo trata das perguntas abertas, nas quais eles respondem o que é autonomia, porque ela pode ser trabalhada nas aulas, como e quais as estratégias de avaliação deste trabalho. 
O primeiro bloco teve análise com ênfase quantitativa, sendo os resultados expressos através de gráficos; o segundo teve análise com ênfase qualitativa. Cada uma das análises será apresentada separadamente.

Bloco 1- perguntas fechadas.

A primeira Questão objetivou observar qual a perspectiva dos professores quanto às finalidades do PEEJ e, de forma mais específica, observar se consideram o desenvolvimento da autonomia uma dessas finalidades. A questão perguntou "Quais as finalidades do Esporte no Programa onde você trabalha"? Foram apresentadas oito opções, das quais os professores deveriam sinalar ao menos quatro. Conforme demonstra o gráfico 2 , todos sinalaram o desenvolvimento da autonomia.

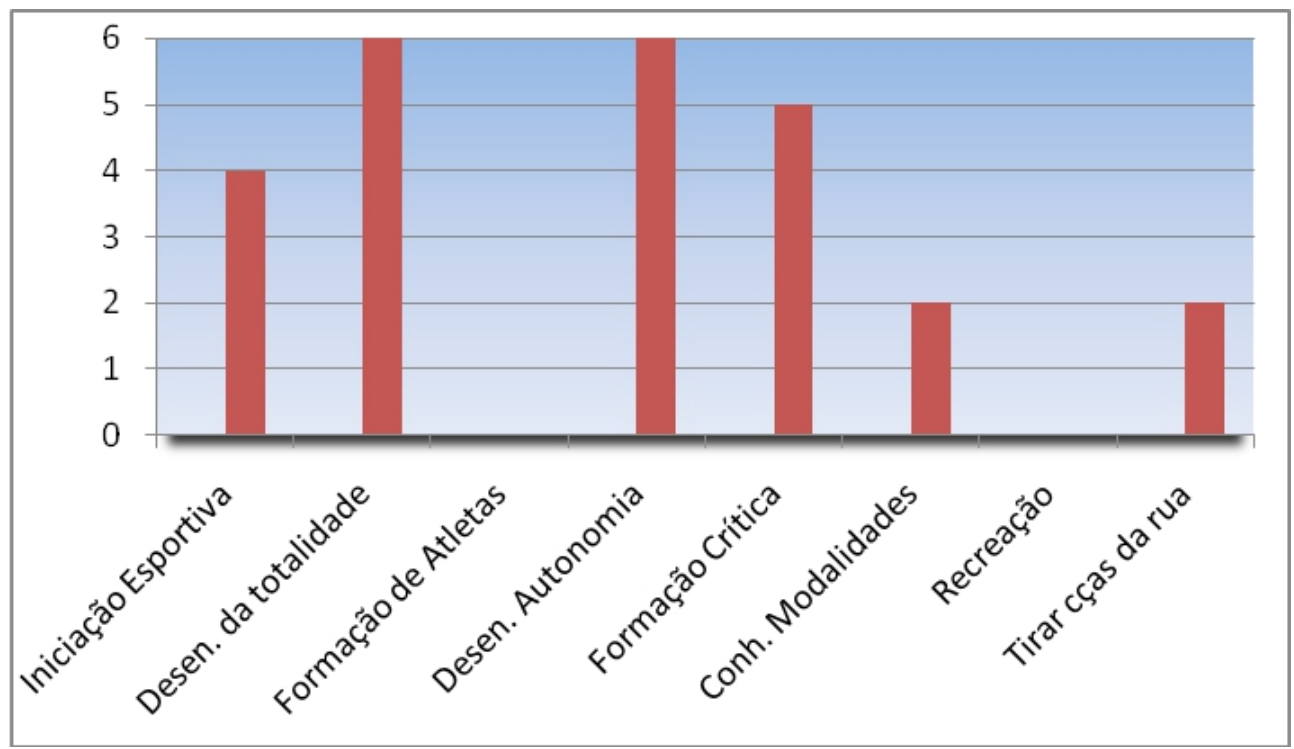

Gráfico 2: Finalidades do esporte no PEEJ

A seguinte resposta fechada requisitada dos entrevistados foi se "A autonomia pode ser trabalhada nas aulas de Esporte?" Sim Não__ ? Todos declaram que sim, conforme o gráfico 3. Complementava a questão o pedido de uma justificativa aberta, que será analisada posteriormente neste artigo. 


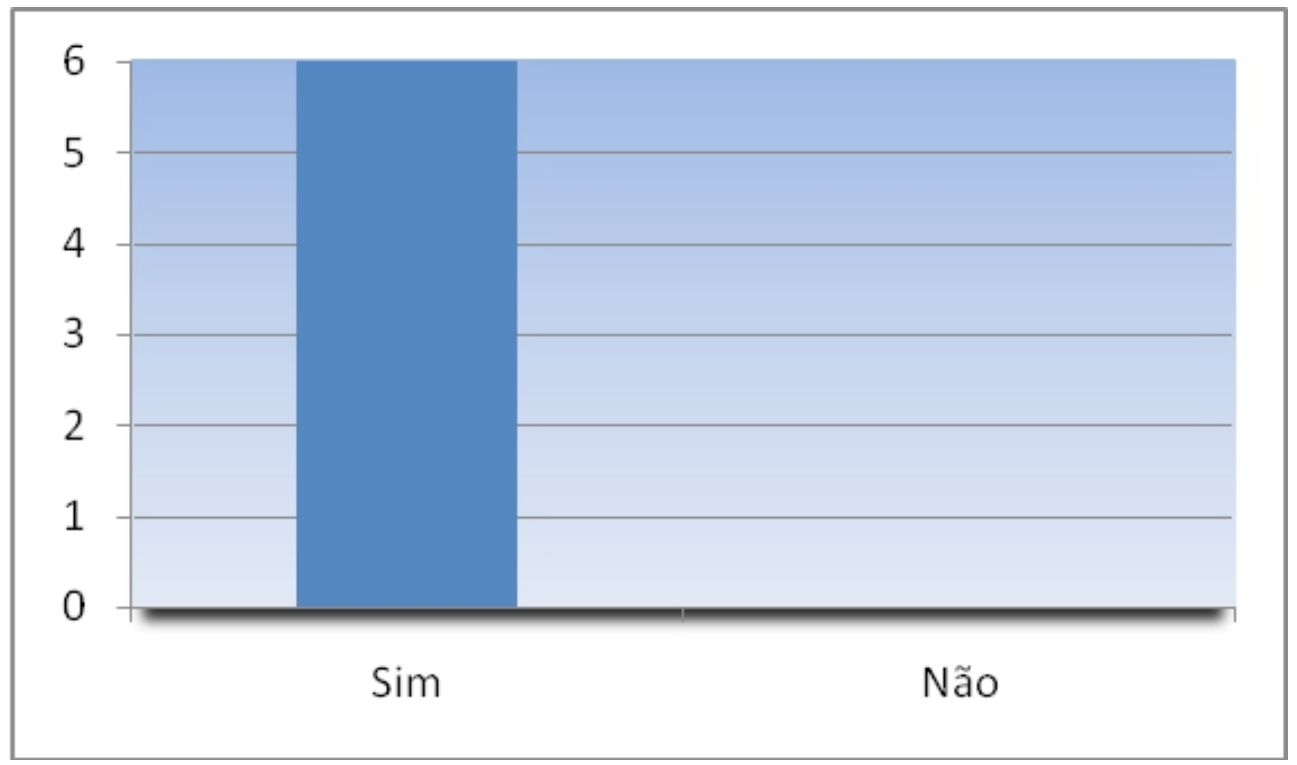

Gráfico 3: Trabalho de autonomia nas aulas

A questão 4 tinha estrutura semelhante, perguntando: "Você planeja aulas com o objetivo de trabalhar a autonomia? Sim Não Como"? Todos declaram incluir a autonomia em seu planejamento (gráfico 4):

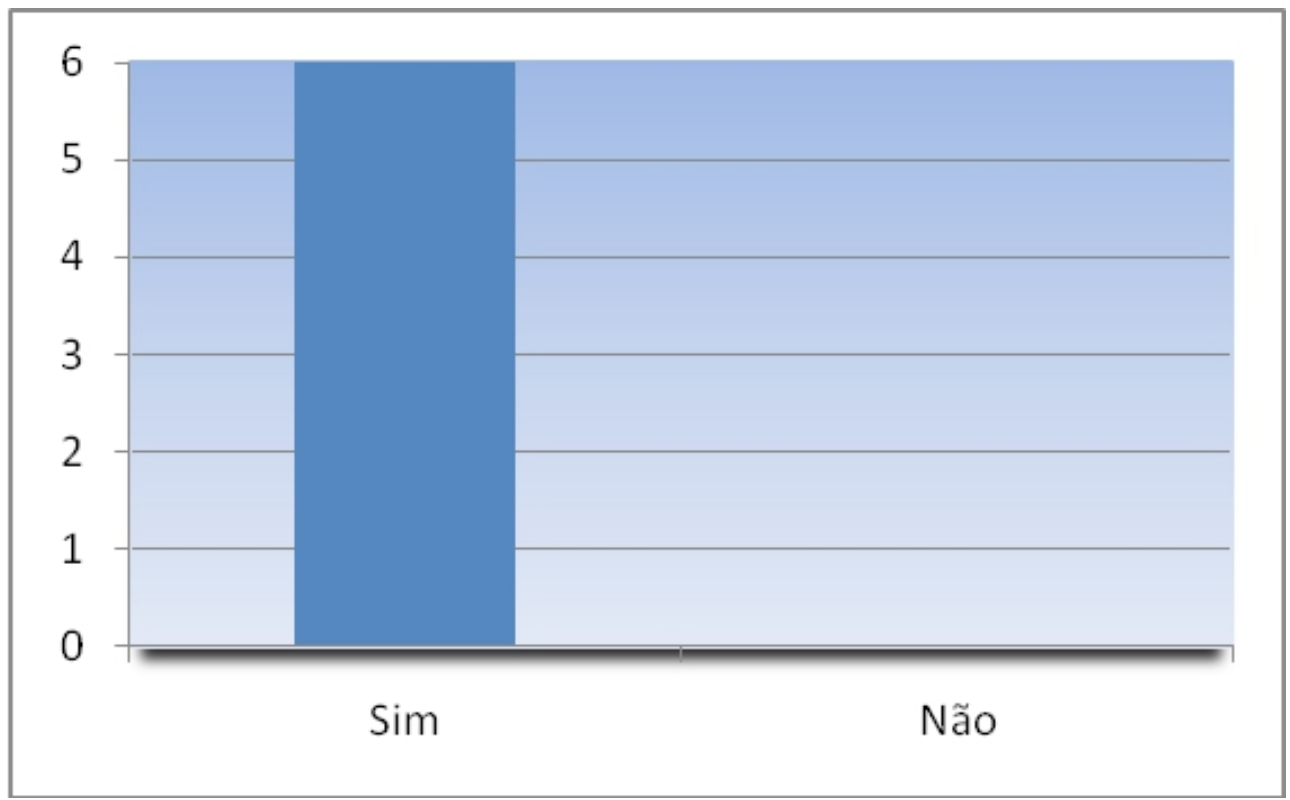

Gráfica 4: Objetivo de trabalhar a autonomia

Analisando as respostas dos professores às questões fechadas, podemos perceber que os professores do PEEJ, além de entenderem que 
a autonomia é uma das finalidades do Esporte dentro do Programa ( $100 \%$ deles), acreditam ser possível trabalhar o tema nas suas aulas, bem como todos afirmam planejar suas aulas voltadas ao objetivo de trabalhar a autonomia (100\%). Porém, diante da análise de 50 planos de aula dos mesmos, apenas 04 professores buscaram planejá-las com o tema autonomia (correspondendo a $66,6 \%$ dos professores). Os Sujeitos 4 e 5 foram os que mais planejaram aulas incluindo a autonomia na dimensão atitudinal, totalizando $28 \%$ dos objetivos das aulas nesta dimensão. E a dimensão conceitual, apresentada apenas no Sujeito 2 correspondeu a $8 \%$ dos objetivos planejados.

É papel do professor oferecer um ambiente favorável em suas aulas para que os alunos possam agir com autonomia (FREIRE e SCAGLIA, 2006; FERREIRA, 2009). Mais que isso, é fundamental que o professor o faça de forma consciente, ou seja, planejada, para que este conteúdo saia do currículo oculto e passe a incorporar o currículo "vivo", ampliando a possibilidade de aprendizagem do aluno e transposição da mesma para as questões do dia a dia. Isso significa que a autonomia deve passar a ser um tema presente nas aulas de forma planejada e consciente e não apenas no discurso, como afirma Ducker , (2004, p.41) em relação às aulas de Educação Física: "existe um discurso avançado e progressista, mas uma prática extremamente conservadora."

Concluindo o primeiro bloco, observamos incoerência entre as respostas dos professores e o conteúdo de seus planos de aula, visto que todos responderam que estimulam a autonomia em suas aulas, porém $34,4 \%$ dos professores não planejaram nenhuma aula sobre este tema, em nenhuma das dimensões. Vale lembrar que o PEEJ tem um documento denominado Planejamento Anual das aulas de Esporte, o qual apresenta como uma das finalidades o desenvolvimento da autonomia para as turmas de 12 a 14 anos. Entretanto, a presença da autonomia nos planos de aula não chegou a 7,4 \% das aulas planejadas, uma vez que foram analisados 300 planos de aula e somente 22 deles faziam alusão à autonomia.

Bloco 2 - perguntas abertas

O segundo momento da análise do questionário teve por ênfase a análise qualitativa, com a interpretação das respostas escritas pelos professores. A interpretação dos dados é o momento final da pesquisa, 
em que o investigador relaciona os dados coletados que serão analisados à luz do referencial teórico (QUEIROZ, 1988), na expectativa de responder à pergunta de investigação, em nosso caso: "os professores do PEEJ, responsáveis pelos alunos entre 12 e 15 anos, de fato contemplam a autonomia na sistematização de suas aulas"?

A primeira pergunta de natureza aberta dizia: "Para você, o que é autonomia"? O Quadro 1 descreve as respostas obtidas:

\begin{tabular}{|c|c|c|c|c|c|}
\hline SUJEITO 1 & SUJEITO 2 & SUJEITO 3 & SUJEITO 4 & SUJEITO 5 & SUJEITO 6 \\
\hline $\begin{array}{l}\text { Independência } \\
\text { de pensamentos, } \\
\text { criatividade, } \\
\text { resolver } \\
\text { problemas por si } \\
\text { só. }\end{array}$ & $\begin{array}{l}\text { Tomar decisões } \\
\text { por ele mesmo, } \\
\text { sabendo que as } \\
\text { mesmas trazem } \\
\text { uma } \\
\text { responsabilidade. }\end{array}$ & $\begin{array}{l}\text { É característica } \\
\text { individual de } \\
\text { tomar decisões, } \\
\text { atitudes de } \\
\text { realizar tarefas, } \\
\text { ser crítico, } \\
\text { porém reflexivo } \\
\text { diante das } \\
\text { decisões. }\end{array}$ & $\begin{array}{l}\text { Possuir suas } \\
\text { próprias } \\
\text { opiniōes e tomar } \\
\text { suas próprias } \\
\text { decisões, saber } \\
\text { distinguir o que } \\
\text { é certo ou } \\
\text { errado. }\end{array}$ & $\begin{array}{l}\text { É a pessoa ter a } \\
\text { iniciativa em } \\
\text { tomar alguma } \\
\text { decisão, se } \\
\text { colocar perante } \\
\text { um grupo, sendo } \\
\text { questionador e } \\
\text { crítico quando } \\
\text { necessário. }\end{array}$ & $\begin{array}{l}\dot{E} \text { a capacidade } \\
\text { que o indivíduo } \\
\text { desenvolve de } \\
\text { tomar suas } \\
\text { próprias } \\
\text { decisões, ter seu } \\
\text { senso crítico de } \\
\text { resolver } \\
\text { situações } \\
\text { problemas. }\end{array}$ \\
\hline
\end{tabular}

Quadro 1: O que é autonomia

Podemos perceber através das respostas um consenso que autonomia é a capacidade do indivíduo de tomar suas próprias decisões e resolver problemas. Se buscarmos na literatura, a concepção dos colaboradores não está errada, porém limita-se a uma questão individual, sem levar em conta o coletivo. Segundo Kamii, (1995) a essência da autonomia é:

"que as crianças tornem-se aptas a tomar decisões por si mesmas. Mas a autonomia não é a mesma coisa que a liberdade completa. A autonomia significa levar em consideração os fatores relevantes para decidir agir da melhor forma para todos. Não pode haver moralidade quando se considera apenas o próprio ponto de vista. (KAMII, 1995, p. 108)

Portanto, percebemos que a autonomia, embora seja a tomada de decisão individual, deve sempre ser pautada no pensamento e na consciência coletiva. Freire e Scaglia (2006), nos conduzem a refletir a temática:

"Quantos de nós poderiam, hoje, ter essa capacidade de se autogovernar, de tomar decisões com independência, de acordo com nossa própria consciência, sem, contudo, realizar ações contrá- 
rias à vida - à nossa e à dos outros, sejam eles humanos, árvores, rios ou bichos? (FREIRE; SCAGLIA, 2006, P. 114)

Sabemos que diversos fatores interferem no processo de formação da autonomia do aluno e a intervenção do professor é uma delas. Entretanto, para promovê-la, é necessário que o professor tenha, antes de tudo, clareza do conceito, o que se dá de forma parcial no Programa estudado.

A seguinte questão aberta se referia à finalidade do trabalho com a autonomia nas aulas de esporte, em complemento à possibilidade de abordá-la: "A autonomia pode ser trabalhada nas aulas de Esporte? Sim __ Não __. Por quê"? Como apresentado anteriormente, todos os Sujeitos responderam que Sim. A Quadro 2 apresenta as respostas dos professores ao porquê:

\begin{tabular}{|c|c|c|c|c|c|}
\hline SUJEITO 1 & SUJEITO 2 & SUJEITO 3 & SUJEITO 4 & SUJEITO 5 & SUJEITO 6 \\
\hline $\begin{array}{l}\text { Nas atividades } \\
\text { trabalha-se } \\
\text { autonomia } \\
\text { direta ou } \\
\text { indiretamente, } \\
\text { cada um age da } \\
\text { forma que achar } \\
\text { certo. }\end{array}$ & $\begin{array}{l}\text { Porque trabalha o } \\
\text { individuo nas suas } \\
\text { três dimensões, } \\
\text { mostramos pra ele } \\
\text { a importância de } \\
\text { suas atitudes e } \\
\text { responsabilidades, } \\
\text { dentro do Esporte } \\
\text { ou através dele. }\end{array}$ & $\begin{array}{l}\text { Porque deverão } \\
\text { ter autonomia } \\
\text { para elaborar } \\
\text { estratégias, } \\
\text { expressar } \\
\text { opiniões que } \\
\text { levem à equipe } \\
\text { a realizar os } \\
\text { objetivos, } \\
\text { favorecendo } \\
\text { principalmente } \\
\text { as questões } \\
\text { atitudinais. }\end{array}$ & $\begin{array}{l}\text { O Esporte } \\
\text { proporciona } \\
\text { momentos em } \\
\text { que você precisa } \\
\text { ter autonomia } \\
\text { para saber o que } \\
\text { deve e que } \\
\text { não deve ser } \\
\text { feito, momentos } \\
\text { em que você } \\
\text { forma sua } \\
\text { opinião e coloca } \\
\text { isso em prática. }\end{array}$ & $\begin{array}{l}\text { Nas aulas o } \\
\text { aluno } \\
\text { estimulado a } \\
\text { todo o momento } \\
\text { com } \\
\text { fundamentos, } \\
\text { regras, } \\
\text { estratégias. O } \\
\text { educando é } \\
\text { estimulado a ter } \\
\text { autonomia } \\
\text { tomando } \\
\text { decisões mais } \\
\text { adequadas para } \\
\text { cada situação. }\end{array}$ & $\begin{array}{l}\text { O Esporte } \\
\text { oferece } \\
\text { inúmeras } \\
\text { situações } \\
\text { diferentes } \\
\text { (conflitos, } \\
\text { problemas em } \\
\text { grupo, } \\
\text { estratégias...), } \\
\text { onde será } \\
\text { necessário o } \\
\text { individuo tomar } \\
\text { suas decisões, se } \\
\text { posicionar. }\end{array}$ \\
\hline
\end{tabular}

Quadro 2: Autonomia nas aulas de esporte

Considerando que uma das finalidades do PEEJ é a formação de cidadãos, autônomos, críticos e reflexivos, sendo o Esporte um dos conteúdos deste universo educacional, não há motivos para a autonomia não ser um dos conteúdos desenvolvido nas aulas. Até mesmo porque o Esporte favorece para um desenvolvimento do indivíduo como um todo, tanto no seu aspecto motor, cognitivo, quanto afetivo-social, facilitando assim, a formação da autonomia dos alunos (PAES e BALBINO 2009; GALATTI et al, 2008; GALATTI, DARIDO e PAES, 2010).

Darido e Rangel, (2005), consideram que uma das razões de trabalhar com a autonomia nas aulas de Educação Física escolar é para que os alunos sejam autônomos para continuar praticando atividade física 
de forma regular, apreciar um jogo, posicionar-se criticamente sobre questões da prática e do contexto sócio-cultural que envolve. A proposta da prática esportiva do Programa Social estudado, assim como da maioria das iniciativas dessa natureza (HIRAMA, 2008), se assemelha aos intuitos da Educação Física escolar, embora possam se expandir para a especilização em determinada modalidade esportiva; sendo assim, a educação pelo esporte passa pela autonomia, na possibilidade de transição das vivências no ambiente esportivo para a vida em sociedade (BALBINO, 2001).

Paes e Balbino (2009), Balbino (2001) e Freire e Scaglia (2006) apontam, ainda, que o ensinar pelo esporte deve estar comprometido com a autonomia do ser humano, para que o aluno seja capaz de reconhecer a noção de dependência da coletividade, permitindo à crianças e adolescentes identificarem sua condição humana, valorizando a capacidade de resolver problemas, contribuindo para a formação do indivíduo de forma plena.

Entretanto, observamos novamente dificuldades dos professores em apontar de forma clara o motivo de se trabalhar com a autonomia nas aulas, as respostas ficaram mais próximas da forma de se fazer isso, do que o porquê: as respostas obtidas dos colaboradores $1,3,5$ e 6 não contemplam de forma clara o motivo de se trabalhar com a autonomia nas aulas, as respostas ficaram mais próximas da forma de se fazer isso, do que o porquê. Os colaboradores 2 e 4 consideraram melhor as razões, sendo que o Sujeito 4, de uma certa forma, se aproxima com os motivos supracitados pelos autores estudados.

Os entrevistados também responderam a como abordam a autonomia nas aulas, na questão: Você planeja aulas com o objetivo de trabalhar a autonomia? Sim Não . Como? Nesta questão, todos os colaboradores responderam que $\overline{\mathrm{Sim}}$. Cabe a discussão do como, apresentado na Quadro 3: 


\begin{tabular}{|c|c|c|c|c|c|}
\hline SUJEITO 1 & SUJEITO 2 & SUJEITO 3 & SUJEITO 4 & SUJEITO 5 & SUJEITO 6 \\
\hline $\begin{array}{l}\text { Não com tanta } \\
\text { freqüência, } \\
\text { porque a faixa } \\
\text { etária na qual eu } \\
\text { trabalho já sabe } \\
\text { e conhece o que } \\
\text { é autonomia. } \\
\text { Quando é } \\
\text { objetivo de aula } \\
\text { trabalho } \\
\text { geralmente na } \\
\text { resolução de } \\
\text { problemas, } \\
\text { individualmente } \\
\text { e em conjunto. }\end{array}$ & $\begin{array}{l}\text { Deixando tomar } \\
\text { decisões, } \\
\text { escolher como } \\
\text { será o trabalho } \\
\text { ou até mesmo o } \\
\text { que cada um } \\
\text { pode fazer para } \\
\text { melhorar a } \\
\text { turma e as aulas. }\end{array}$ & $\begin{array}{l}\text { Com jogos de } \\
\text { construção, mas } \\
\text { no Esporte } \\
\text { quando } \\
\text { estabeleço um } \\
\text { capitão por } \\
\text { equipe onde ele } \\
\text { tem total } \\
\begin{array}{ll}\text { autonomia para } \\
\text { elaborar } \\
\text { estratégias de } \\
\text { jogo, na } \\
\text { arbitragem. na }\end{array}\end{array}$ & $\begin{array}{l}\text { Proporcionando } \\
\text { momentos em que } \\
\text { os alunos } \\
\text { precisam decidir o } \\
\text { que será feito, } \\
\text { utilizando suas } \\
\text { próprias } \\
\text { estratégias para o } \\
\text { desenvolvimento } \\
\text { de uma } \\
\text { determinada } \\
\text { atividade. }\end{array}$ & $\begin{array}{l}\text { São estimuladas } \\
\text { atividades onde } \\
\text { o aluno é levado } \\
\text { a pensar e } \\
\text { questionar sobre } \\
\text { determinado } \\
\text { assunto e ter a } \\
\text { liberdade em } \\
\text { buscar a melhor } \\
\text { maneira de } \\
\text { realizar um } \\
\text { movimento e } \\
\text { situações onde } \\
\text { os alunos } \\
\text { trabalham em } \\
\text { grupo. }\end{array}$ & $\begin{array}{l}\text { Propondo } \\
\text { situações para } \\
\text { eles resolverem, } \\
\text { tomar decisões } \\
\text { em grupo, } \\
\text { exigindo } \\
\text { conversa e } \\
\text { discussão para } \\
\text { chegar a uma } \\
\text { posição única: } \\
\text { estratégia de } \\
\text { jogo, divisão de } \\
\text { equipe. }\end{array}$ \\
\hline
\end{tabular}

Quadro 3: Como a autonomia é planejada nas aulas

Para discutirmos esse ponto metodológico retomamos Ferreira (2009), Galatti et. Al. 2008 e Scaglia e Souza (2004), que colocam que para que haja um estímulo à autonomia dos alunos o professor deverá estimular a criatividade através de soluções de problemas motores e cognitivos, respeitando o conhecimento prévio do aluno, mas ao mesmo tempo, ampliando este universo, permitindo ao aluno tomar consciência de suas ações.

As respostas dos colaboradores se aproximam da perspectiva dos autores, quando oferecem em suas aulas momentos de discussão, troca de idéias e resolução de problemas entre os alunos. Porém, os Sujeitos 1 e 6, na análise dos Planos de Aula, não tinham a autonomia como objetivo em nenhuma delas, portanto, é questionável se este trabalho de fato ocorre de forma consciente por parte desses professores.

Segundo Santana (2003, p.52), temos, como possibilidades dentro das aulas de Esporte o desenvolvimento da autonomia do aluno ao:

Participar da construção das regras de determinado jogo, cooperar com um companheiro que se encontra em dificuldades, reunir-se em grupo, opinar quando o grupo está reunido, respeitar as opiniões das pessoas do grupo, conviver com as diferenças dos outros, solidarizar-se com essas diferenças, assumir responsabilidades, trocar informações, propor alternativas, ceder, interceder [...]. (SANTANA, 2003, p.52)

Ampliando, o autor aponta que o método aplicado pelo professor para o estímulo da autonomia do aluno deve ser "ativo", portanto, a 
criança deve agir sobe o que pretende conhecer, tendo ciência de que os valores morais são construídos e não transmitidos.

Desta forma, é fundamental que o professor, ao planejar suas aulas, tenha intenções claras de desenvolver a autonomia dos alunos, pois é um trabalho que exige ações direcionadas e que, se o professor não planejá-las as possibilidades de significado aos alunos sejam menores, e consequentemente, o trabalho não será tão efetivo.

Por fim, os professores foram questionados sobre a utilização ou não de estratégias de avaliação do desenvolvimento da autonomia junto aos alunos, através da questão: "Você tem alguma estratégia para avaliar se há resultados deste trabalho relacionado à autonomia"? As respostas podem ser observadas na Quadro 4:

\begin{tabular}{|c|c|c|c|c|c|}
\hline SUJEITO 1 & SUJEITO 2 & SUJEITO 3 & SUJEITO 4 & SUJEITO 5 & SUJEITO 6 \\
\hline $\begin{array}{l}\text { Dentro das } \\
\text { atividades } \\
\text { propostas, em } \\
\text { uma atividade } \\
\text { especifica que } \\
\text { vai de encontro } \\
\text { com o andar do } \\
\text { trabalho e } \\
\text { atitude deles } \\
\text { dentro e fora do } \\
\text { ambiente que } \\
\text { nos } \\
\text { encontramos. }\end{array}$ & $\begin{array}{l}\text { Observação dos } \\
\text { alunos durante o } \\
\text { semestre e seus } \\
\text { comportamentos } \\
\text { durante as aulas } \\
\text { nas paradas para } \\
\text { rodas de } \\
\text { conversa ou até } \\
\text { mesmo dentro } \\
\text { das aulas. }\end{array}$ & $\begin{array}{l}\text { A cada aula que } \\
\text { escolho um } \\
\text { capitão ou líder } \\
\text { que fica } \\
\text { responsável } \\
\text { durante toda a } \\
\text { aula e nos } \\
\text { momentos finais } \\
\text { de debate, onde } \\
\text { todos discutem } \\
\text { o que foi } \\
\text { trabalhado, mas } \\
\text { podem pedir a } \\
\text { opinião ao } \\
\text { capitão do dia. }\end{array}$ & $\begin{array}{l}\text { Observações e } \\
\text { questionamentos } \\
\text { durante as aulas. }\end{array}$ & $\begin{array}{l}\text { Geralmente } \\
\text { utilizo de } \\
\text { trabalhos em } \\
\text { grupo onde os } \\
\text { alunos tem a } \\
\text { liberdade de } \\
\text { dividir tarefas, } \\
\text { tomar decisões } \\
\text { adequadas para } \\
\text { cada situações. } \\
\text { Ter atitudes que } \\
\text { o fazem se } \\
\text { destacar perante } \\
\text { o grupo. }\end{array}$ & $\begin{array}{l}\text { Propor situações } \\
\text { para eles como } \\
\text { foi citado na } \\
\text { resposta } \\
\text { anterior, } \\
\text { situações que } \\
\text { surgem durante } \\
\text { um coletivo pré- } \\
\text { desportivo. }\end{array}$ \\
\hline
\end{tabular}

Quadro 4: Estratégias de avaliação utilizadas nas aulas de autonomia

A avaliação ainda é um campo carente de estudos mais profundos na Pedagogia do Esporte. Percebemos que há uma dificuldade dos professores em avaliar suas aulas, ainda mais quando estas não estão relacionadas aos conteúdos motores.

Segundo Darido e Rangel, (2005), a avaliação na Educação Física deve contemplar as três dimensões do conteúdo: conceitual, procedimental e atitudinal. Dentro da análise dos Planos de Aula feita nesta pesquisa, a autonomia foi citada nas dimensões Conceitual e Atitudinal, portanto, as estratégias de avaliação dos professores deveriam ser pautadas nestas duas dimensões. Porém, pudemos perceber uma variação entre os Sujeitos, sendo que os Sujeitos 1, 2, 5 e 6 têm um foco maior na avaliação em relação às atitudes dos alunos, o Sujeito 3, um foco maior na dimensão conceitual, e apenas o Sujeito 4 mesclou entre as duas dimensões. É curioso, ainda, que os colaboradores 1 e 6 te- 
nham declarado avaliar a autonomia, ainda que a mesma não conste em seus planos de aula.

Para melhor compreender o colocado acima, Rossetto Junior, Costa e D'Angelo (2008) nos apontam estratégias de avaliação dentro das dimensões. Na conceitual o foco é na situação problema, onde o professor irá verificar a aplicação dos conceitos nas situações propostas. Na dimensão atitudinal, o professor irá observar as atitudes dos alunos em situações de conflito, debate, expressão de opiniões e argumentação. Portanto, transferindo este conhecimento para a autonomia, o professor deverá em suas aulas, além de observar as atitudes dos alunos em situações conflitantes (como já apontado de forma clara pelos Sujeitos 5 e 6), deverá propor situações para que os mesmos apliquem os conceitos aprendidos sobre autonomia nas situações propostas.

\section{Considerações finais:}

Sendo o Esporte um fenômeno de múltiplas possibilidades, entre sujeitos, cenários e significados, podemos afirmar que um dos significados dentro do cenário educacional é a formação da autonomia do aluno. O caso do PEEJ atende a essa dimensão ao incluir o desenvolvimento da autonomia dentre as finalidades do Esporte no Programa. Porém, ao estudarmos os planos de aulas dos professores e analisar sua perspectiva acerca da autonomia e sua inclusão entre os conteúdos das aulas, as dificuldades aparecem.

Embora a autonomia seja citada por diversos autores, sua aplicação de fato e intencional é pouco discutida, sendo uma primeira contribuição deste estudo a delineamento de uma possibilidade de investigação do tema in locu. A literatura em Educação Física é redundante ao sinalizar a formação do cidadão autônomo como um de seus objetivos; o mesmo se dá nos estudos em Pedagogia do Esporte. Mas ainda são necessários estudos que dêem subsídios mais concretos para que o professor de fato o faça, articulando a apresentação do conceito acompanhadas de possibilidades de intervenção e avaliação. Tal fato pode ser apontado como um agravante para que os professores de esporte ampliem sua compreensão e, por conseqüência, prática pedagógica em relação à autonomia.

Por outro lado, é fundamental que os professores busquem a formação continuada e que os Programas Esportivos, independentemente do cenário em que se estabeleçam e sobretudo em Programas Sócio- 
esportivos, esclareçam aos profissionais envolvidos seus objetivos pedagógicos e promovam ações de estudo da proposta do programa esportivo oferecido, buscando uma compreensão coerente dos conteúdos que devem ser trabalhados, assim como construindo estratégias conjuntas para sua organização, sistematização, aplicação e avaliação.

\title{
Pedagogy of Sport and autonomy: a study in social project of non formal edu- cation
}

\begin{abstract}
The study focuses on the educational perspective of the sport in social projects, especially in dealing with autonomy. It analyzes the behavior of teachers working on "Youth and Sport Education Program" (PEEJ) in Taubaté-SP, in order to confront the inclusion or otherwise of encouraging autonomy in classes planning with the description that the teachers do about their practice in relation to encouraging autonomy in the classroom routine. The study metodological structure includes an initial review, followed by analysis of 50 Sessions Plans PEEJ of 6 teachers, who also responded to a semi-structured questionnaire on the subject autonomy and its implementation over school sports.
\end{abstract}

Keywords: Sport - Social Project - Autonomy

Pedagogía del Deporte y la autonomía: un estudio en el proyecto social de la educación no formal

\section{Resumen}

La investigación enfoca la perspectiva educativa del deporte en Proyectos Sociales, en especial no referente a la autonomía. Para tal, analiza la conducta didáctica de profesores del "Programa Ensino Esporte e Juventude (PEEJ) del Ayuntamiento de Taubaté-SP, a fin confrontar la inclusión o no del estímulo a la autonomía en el planteamiento, con la descripción que los propios profesores hacen de la práctica en relación al estímulo a la autonomía en el cotidiano de las clases. La estructuración metodológica de la investigación incluye una revisión bibliográfica, seguida del análisis de 50 planes de clase de 6 profesores del PEEJ, que también rellenaron un cuestionario semi-estructurado a cerca del tema autonomía y su aplicación en las clases deportivas.

Palabras clave: Deporte - Proyecto Social - Autonomía

\section{Referências}

BALBINO, H. F. Jogos desportivos coletivos e os estímulos das inteligências múltiplas: bases para uma proposta em pedagogia do esporte. 2001. 142f. Dissertação (Mestrado em Educação Física) Faculdade de Educação Física, Universidade Estadual de Campinas, Campinas. 
BLÁZQUEZ, D.S. La Iniciación Deportiva. Barcelona: INDE, 1995.

DARIDO, S. C.; RANGEL, I. C.A: Educação Física na Escola: implicações para a prática pedagógica. Rio de Janeiro: Guanabara Koogan, 2005, p. 65.

DEMARTINI, Z.B.E.; LANG, A.B.S.G. Educando Para o Trabalho: família e escola como agências educadoras. São Paulo: Loyola, 1985.

DUCKUR, L. C.B.: Em busca de indivíduos autônomos nas aulas de Educação Física. Campinas: autores associados, 2004, p. 41.

FERREIRA, H. B. Pedagogia do Esporte: identificação, discussão e aplicação de procedimentos pedagógicos no processo de ensino-vivência e aprendizagem da modalidade basquetebol. 2009. Dissertação (Mestrado em Educação Física) - Faculdade de Educação Física, Universidade Estadual de Campinas, Campinas.

FREIRE, J. B.; SCAGLIA, A. J.: Educação como prática corporal. São Paulo: Scipione, 2006, p. 114.

GALATTI, L. R. et. al. Pedagogia do Esporte: procedimentos pedagógicos aplicados aos jogos esportivos coletivos. Revista Conexões, Campinas, v. 6, n. especial, 2008. p. 404-415. Disponível em: $<$ http://polaris.bc.unicamp.br/seer/fef/viewarticle.php?id=319\&layout=abstract $>$ Acesso em: 12 mai. 2009

GALATTI, L.; PAES, R.; DARIDO, S. Pedagogia do Esporte: livro didático aplicado aos Jogos Esportivos Coletivos.. Motriz. Revista de Educação Física. UNESP, América do Norte, 16, abr. 2010. Disponível em: http://www.periodicos.rc.biblioteca.unesp.br/index.php/motriz/article/view/3238. Acesso em: 20 Set. 2010.

GALATTI, L.R. Esporte e clube sócio-esportivo: percurso, contextos e perspectivas a partir de estudo de caso em clube esportivo espanhol. 2010 Tese (Doutorado em Educação Física) - Faculdade de Educação Física, Universidade Estadual de Campinas, Campinas.

HIRAMA, L. Algo para Além de Tirar as Crianças da Rua: o papel da pedagogia do esporte em projetos socioeducativos. 2008. Dissertação (Mestrado em Educação Física) - Faculdade de Educação Física, Universidade Estadual de Campinas, Campinas. 
KAMII, C. :A criança e o número. $7^{\text {a }}$ Ed. - Campinas: Papirus, 1995, p. 81.

MATTOS, M. G., ROSSETTO JÚNIOR, A.; BLECHER, S.: Metodologia da pesquisa em educação física: construindo sua monografia, artigos e projetos. - $3^{\mathrm{a}}$ edição. São Paulo: Phorte, 2008.

PAES, R; BALBINO, H.: A pedagogia do Esporte e os Jogos Coletivos. In: De Rose, D.: Esporte e atividade física na infância e na adolescência: uma abordagem multidisciplinar. $2^{\mathrm{a}}$ edição - Porto Alegre: Artmed, 2009. P: $73-83$

PIAGET, J.: O Juízo Moral na criança. São Paulo: Summus, 1994, p. 23.

QUEIROZ, M. I.P. Relatos Orais: do "indivizível" ao "divizível". In: VON SIMSON, O. R.M. (org.). Experimentos com História Oral: Itália-Brasil. São Paulo: Vértice, 1988.

ROSSetTo JUniOR, A,; COSTA, C. M.,; D’ANGelO, F. L.: Práticas pedagógicas reflexivas em esporte educacional: unidade didática como instrumento de ensino aprendizagem. São Paulo: Phorte, 2008 .

SANTANA, W. A pedagogia do Esporte na infância e complexidade. In: PAES, R. e BALBINO, H.: A Pedagogia do Esporte: Contextos e Perspectivas. Rio de Janeiro: Guanabara Koogan, 2006, P:2.

SANTANA W.C. Dissertação de Mestrado: A Pedagogia do Esporte e a moralidade infantil. UNICAMP, Campinas: 2003.

SCAGLIA, A. J.; SOUZA, A.: A Pedagogia do Esporte. In: Comissão de Especialistas - ME. Dimensões pedagógicas do esporte. Brasília: $\mathrm{UNB} / \mathrm{Cad}, 2004$.

SCAGLiA, A. J.; REVERDITO, R. S.: Pedagogia do Esporte: jogos coletivos de invasão. São Paulo: Phorte, 2009.

ZABALA A., A prática educativa: como ensinar. Porto Alegre: ArtMed, 1998. 
Recebido em: 13/08/2010

Revisado em: 01/09/2010

Aprovado em: 20/09/2010

\section{Endereço para correspondência}

giseleviola_ef@yahoo.com.br

Roberto Rodrigues Paes

Universidade Estadual de Campinas

Departamento de Ciências do Esporte

Rua Érico Verrísimo, 701

Barão Geraldo

13083-851 - Campinas, SP - Brasil

Caixa-Postal: 6134 